\title{
Calibration of international capacity models for dual lane roundabouts during saturation flow condition
}

\author{
H. M. N. Al-Madani \\ Department of Civil Engineering \& Architecture, \\ University of Bahrain, Bahrain
}

\begin{abstract}
Varying differences in the prediction of roundabout capacities were observed between various international models and field data. This study attempts to calibrate 7 international models for forced flow conditions. These include UK, aaSIDRA, Swiss, US FHWA, HCM, French and German models. These are compared with field data collected from 12 large roundabouts in Bahrain. They are compared considering scattered plots, Root Mean Square Error (RMSE) and t-tests. Each model is calibrated by a trial multiplicative factor which is then adjusted in an iterative manner until best match with actual data is achieved. The calibration adjusts the $\mathrm{Y}$-intercept and the slope of each model. The calibration factors, based on the initial results, showed high variations in the adjustment factors between one model and another. The calibrated models showed substantial improvements and were fairly comparable with actual data. The UK, aaSIDRA and French models, with over $40 \%$ reduction, required the greatest adjustments to suite the field data. The FHWA model required $35 \%$ reduction and the German model required $15 \%$ increase to reasonably fit the field data. The HCM method required no adjustments and the Swiss model required a reduction of $5 \%$. The calibration factors were as follows in respective order: $0.5225,0.515$, $0.585,0.65,1.16,1.0$ and 0.95 . While differences in capacity prediction between one international model and another confuse the practitioners; calibrated models assist them to have just predictions regarding roundabout capacities during forced flow conditions. The developed calibrations require further investigation to reduce the deviation between the calibrated models and the actual data.
\end{abstract}

Keywords: capacity, maximum entry flow, circulating flow, exiting flow, calibration, adjustment factor. 


\section{Introduction}

Roundabout capacity is the maximum sustainable entry flow that an approach can accommodate during a specific period under prevailing traffic, geometric and control conditions. Capacity is different to maximum flow that an intersection can handle [1], which is the practical capacity under high demand volume; i.e. not under prevailing conditions. Hollis et al. [2] and Tenekci et al. [3] defined capacity as the maximum entering flow when the flow is sufficient to cause continuous and persistent queuing. On the other hand, service flow rate, as defined in Highway Capacity Manual 2010 [4], is the maximum directional rate of flow that can be sustained in a given segment under prevailing roadway, traffic and control conditions. The maximum flow that can be accommodated at a roundabout entry depends mainly on the circulating flow around the roundabout that conflicts with the entry flow, exiting flow and the geometric elements of the roundabout. Most of the capacity models are either analytical ones based on gap acceptance, with limited actual observations, or empirical regression ones based on observed geometric and flow parameters. Inconsistent gap acceptance occurs, which has not been accounted for in theory, when drivers reject large gaps or make force entry during congestion, or when other drivers give up their right of way [5]. Furthermore, evaluation of the critical headway is difficult, as for example different vehicle types accepting different gaps [5]. Empirical models showed poor transferability to other countries or other times [5] without being well calibrated. Kimber [6] stated that capacity estimates based on gap acceptance models are not suitable for the application in England. This was due to the problems related to human behavior. Russell and Rys [7] also questioned the validity of gap acceptance models at near capacity conditions. On the other hand, Fisk [8] found regression models to be difficult for frequent application due to large number of data requirements. Micro-simulation techniques are also lately used by some researchers. They typically simulate traffic system on a vehicle-by-vehicle basis by updating position, speed, acceleration, lane position and other variables on small time steps [9]. Stanek and Milam [10] recommended to use macroscopic methods, as FHWA, RODEL, aaSIDRA for the capacity use for unsaturated conditions.

There are several analytical and empirical models for the entry flow estimations. However, capacities estimated through these models widely differ from one model to another $[11,12]$. Such variation calls for calibration and a procedure for matching the various models for the use in various countries. Currently, the UK and the Australian aaSIDRA models are the most famous ones. The question of how good the capacity estimate of each model is, when compared with actual data during forced flow condition in different parts of the world, requires careful investigation. Pratelli [13] found clear differences in capacity estimates when French and Swiss models were compared with actual data in Italy. Overestimation of 25 to $79 \%$ in the capacity was observed. The need for capacity evaluation of various models and software programs, available worldwide, was stressed by Jacquemart [14]. UK model [15] is based on the work carried out by Kimber and Hollis [16, 17] for TRL. It requires 
measurement of extensive geometric parameters. Many researchers simplified the earlier model for specific geometric constants [4, 18]. UK model overestimated roundabout critical lane capacity in USA $[19,20]$. The Australian aaSIDRA capacity method was improved by Akçelik et al. [21, 22] and incorporated in a widely known software called aaSIDRA [1]. The method employs many traffic and few geometric parameters. The Australian model NAASRA was developed by National Association of Australian State Road Authorities [23-25]. The model mainly depends on the circulating flow. The German model is derived from the Tanner and $\mathrm{Wu}$ capacity equation and has been introduced officially into the German Highway Capacity Manual in 2001 $[26,27]$. The detailed formula for entry flow is discussed by $\mathrm{Wu}[28,29]$. The French model is based on the work carried out by Louah [30] which later was incorporated into a model known as GIRABASE [31]. The French model overpredicted the entry capacity when tested on the American roundabouts [19]. At least two models are currently available in the recent US literature; the Highway Capacity Manual (HCM 2010) [4] and the Federal Highway Administration (FHWA) models [19, 32]. According to Robinson and Rodegerdts [18] the FHWA model is based on Wu's model $[28,29]$.

Bahrain models [12] involve exponential and logarithmic terms for different number of entry and circulating lanes. The models are very simplistic and incorporate only circulating flow for dual and triple lane roundabouts. A more extensive model is also available for Bahrain, since wide variations in the estimated capacities were observed when compared with other international models [33]. The model though fitted the actual data well, still showed wide variation with other international models.

\section{Objectives and study approach}

International roundabout entry capacity models widely vary between one method and another. Most of the models are solely based on circulating flow. Seven models are calibrated here so as to suite the regional use during saturated flow condition. All the experimental data are gathered from roundabouts during high demand flows. Field maximum entry flows for 12 roundabouts in Bahrain are compared with seven international models using Root Mean Square Error or Deviation (RMSE), t-tests, standard error of mean and scattered plots. RMSE measures the differences between values predicted by a model and the values actually observed. The international models are then calibrated to match actual entry flows for selected saturated roundabouts in Bahrain using a trial multiplicative factor. The factor is then increased and decreased in iterative manner until best match in capacity between the calibrated model and the field data is achieved. The calibration is mainly adjustment to the Y-intercept and the slope of the models. RMSE and paired t-test is performed in each step for comparison purposes. The maximum entry flow is calibrated as per approach, not per individual or critical lane, since many of the considered models utilize traffic flow per approach entry. Researchers prefer them over individual lane determination [34]. The traffic from the various entry lanes are assumed to 
dissipate at equal rate during congested flows. The calculated capacities are compared with the actual demand. Entering vehicles are considered regardless of their relative lane-positions. The calibration developed here is limited to the use of medium to large roundabouts with triple lanes during heavy flow condition.

\section{Data gathering}

Twelve roundabouts across Bahrain are tested for the investigation. All the roundabouts carried saturated traffic flows and relatively large inscribed diameters. Few roundabouts carried mix dual and triple entry lanes. Only approaches with dual entry lanes are considered in this study. The range of the measured geometric and traffic data have been presented in earlier works [12, 33]. The classified entry traffic flow counts for the selected roundabouts were collected during both morning and evening peaks for each approach. Road Directorate in Bahrain gathered these data manually for the need of this study through classified intersection counts.

\section{Main results}

\subsection{International capacity models}

Field data gathered from 12 roundabouts in Bahrain revealed a mean maximum entry flow of 738 vehicle/h per approach of dual-entry lanes (Table 1). This is considered to be relatively low when compared with 2300 passenger cars/h/lane on an uninterrupted through traffic on a freeway, as specified in HCM 2010 [4]. However, the capacities estimated through various international models showed wide variations among each other and with the field data. While the German model showed the lowest mean, compared with the other seven models and the field data; the aaSIDRA and the UK showed the highest mean for. In fact, the former model showed $14 \%$ lesser entry flow than the actual average of Bahrain.

Table 1: Statistics for dual-lane roundabout capacity for international models.

\begin{tabular}{|c|c|c|c|c|}
\hline \multirow{2}{*}{$\begin{array}{l}\text { Considered } \\
\text { Model }\end{array}$} & \multicolumn{2}{|c|}{ Mean values $(\mathrm{n}=70)$} & \multirow{2}{*}{$\begin{array}{c}\text { Pearson } \\
\text { correlation } \\
\text { with field data }\end{array}$} & \multirow{2}{*}{$\begin{array}{l}\text { RMSE model } \\
\text { vs. field data }\end{array}$} \\
\hline & $\begin{array}{c}\text { Non- calibrated } \\
\text { model }\end{array}$ & $\begin{array}{c}\text { Actual } \\
\text { flow }\end{array}$ & & \\
\hline UK & 1411.0 & 737.8 & 0.611 & 828 \\
\hline aaSIDRA & 1428.0 & 737.8 & 0.560 & 1005 \\
\hline French & 1266.1 & 737.8 & 0.624 & 740 \\
\hline German & 634.9 & 737.8 & 0.466 & 502 \\
\hline Swiss & 775.9 & 737.8 & 0.383 & 631 \\
\hline USHCM & 742.8 & 737.8 & 0.517 & 486 \\
\hline US FHWA & 1136.2 & 737.8 & 0.497 & 688 \\
\hline
\end{tabular}

The latter two models showed over $90 \%$ greater than the actual data. Similarly, the French model showed a higher estimate of around $70 \%$ than the field values. The FHWA model showed a greater average of 54\%. The HCM and Swiss 
models showed a very reasonable match with Bahrain field data. The difference was less than $5 \%$. However, it is worth noting that the Swiss model was developed based on data from small roundabouts.

Confirming the previous findings; the HCM and the German models revealed the least deviation from the field data as per RMSE results (Table 1). The residual differences between the earlier mentioned models and the field data indicate relatively high differences. The aaSIDRA model showed the highest variation, followed by UK, then French models, with the actual field data. The other models though showed far less RMSE values; still are considered to be high. Such variation can clearly be noted when paired differences and t-tests are performed between the predicted capacities and the actual ones. The aaSIDRA, the UK and the French models, as can be observed from Table 2, showed the existence of substantial differences between the actual data and the predicted ones. These are far more than those observed for the HCM, the Swiss and the German models. The latter models are simple empirical equations which are mainly based on circulating flows, when compared with the earlier ones which are based on quite extensive mathematical equations employing many predictors. The paired t-test showed significant differences between the actual data and all the tested models, except the HCM and the Swiss methods. In fact, the HCM and the Swiss models showed significant match with actual data.

Table 2: $\quad$ Paired t-tests and differences between non-calibrated models and field data for dual-lane roundabouts.

\begin{tabular}{|c|c|c|c|c|c|}
\hline \multirow{2}{*}{ Tested Pairs } & \multicolumn{3}{|c|}{ Paired Differences } & \multicolumn{2}{|c|}{ 2-tailed } \\
\cline { 2 - 6 } & Mean & Std. Dev. & SEM & t-test & Significance \\
\hline Entry flow - UK & -673.1 & 484.9 & 58.0 & -11.6 & 0.000 \\
Entry flow - aaSIDRA & -690.2 & 735.6 & 87.9 & -7.9 & 0.000 \\
Entry flow - French & -528.2 & 521.5 & 62.3 & -8.5 & 0.000 \\
Entry flow - German & 103.0 & 494.8 & 62.3 & 1.7 & 0.086 \\
Entry flow - Swiss & -38.1 & 634.1 & 75.8 & -0.5 & 0.617 \\
Entry flow - HCM & -4.9 & 483.8 & 57.8 & -0.1 & 0.990 \\
Entry flow - FHWA & -398.4 & 564.8 & 67.5 & -5.9 & 0.000 \\
\hline
\end{tabular}

Pearson linear Correlation tests showed significant correlation between the actual field data and the various considered models (Table 1). In other words, most of the un-calibrated models are linearly associated with Bahrain data, though not necessarily matching them. However, calibration of such relationship is essential due to the significant differences, resulting in high RMSE and t-tests indicating significant differences (Tables 1 and 2), between the actual field data and the tested models. Therefore, calibration of the Y-intercept and/or the slope of the actual models, by iteratively lowering and raising them, to reasonably match the field data is inevitable so as to be useful for the regional use. 


\subsection{Calibration of international 2 lane-roundabout models}

The best adjustment factors leading to closes match of the predicted entry capacities, of the various tested models, with the actual data are presented in Table 3. The necessary statistics, as mean values and Root Mean Square Error or Residual (RMSE) are presented in the Table along with the multiplicative calibration factors resulting in the lowest RMSE. The actual entry capacities versus various calibrated models are also presented as scattered diagrams in Figures 1 and 2 .

Table 3: Calibration of international roundabout capacity models compared with actual data for large 2-lane roundabouts.

\begin{tabular}{|c|c|c|c|c|c|}
\hline \multirow{2}{*}{$\begin{array}{c}\text { Considered } \\
\text { Model }\end{array}$} & \multirow{2}{*}{$\begin{array}{l}\text { Calibration } \\
\text { factor }\end{array}$} & \multicolumn{2}{|c|}{ Mean values } & \multirow{2}{*}{$\begin{array}{c}\text { Pearson } \\
\text { correlation } \\
\text { with field data }\end{array}$} & \multirow{2}{*}{$\begin{array}{c}\text { RMSE } \\
\text { model vs. } \\
\text { field data }\end{array}$} \\
\hline & & $\begin{array}{c}\text { Calibrated } \\
\text { model }\end{array}$ & $\begin{array}{l}\text { Actual } \\
\text { flow }\end{array}$ & & \\
\hline UK & 0.5225 & 737.3 & 737.8 & 0.611 & 428 \\
\hline aaSIDRA & 0.515 & 735.4 & 737.8 & 0.560 & 471 \\
\hline French & 0.585 & 740.6 & 737.8 & 0.624 & 422 \\
\hline German & 1.16 & 736.4 & 737.8 & 0.466 & 509 \\
\hline Swiss & 0.95 & 737.1 & 737.8 & 0.363 & 613 \\
\hline USHCM & 1.0 & 738.6 & $\begin{array}{l}737.8 \\
\end{array}$ & 0.507 & 486 \\
\hline USFHWA & 0.65 & 738.5 & 737.8 & 0.497 & 479 \\
\hline
\end{tabular}
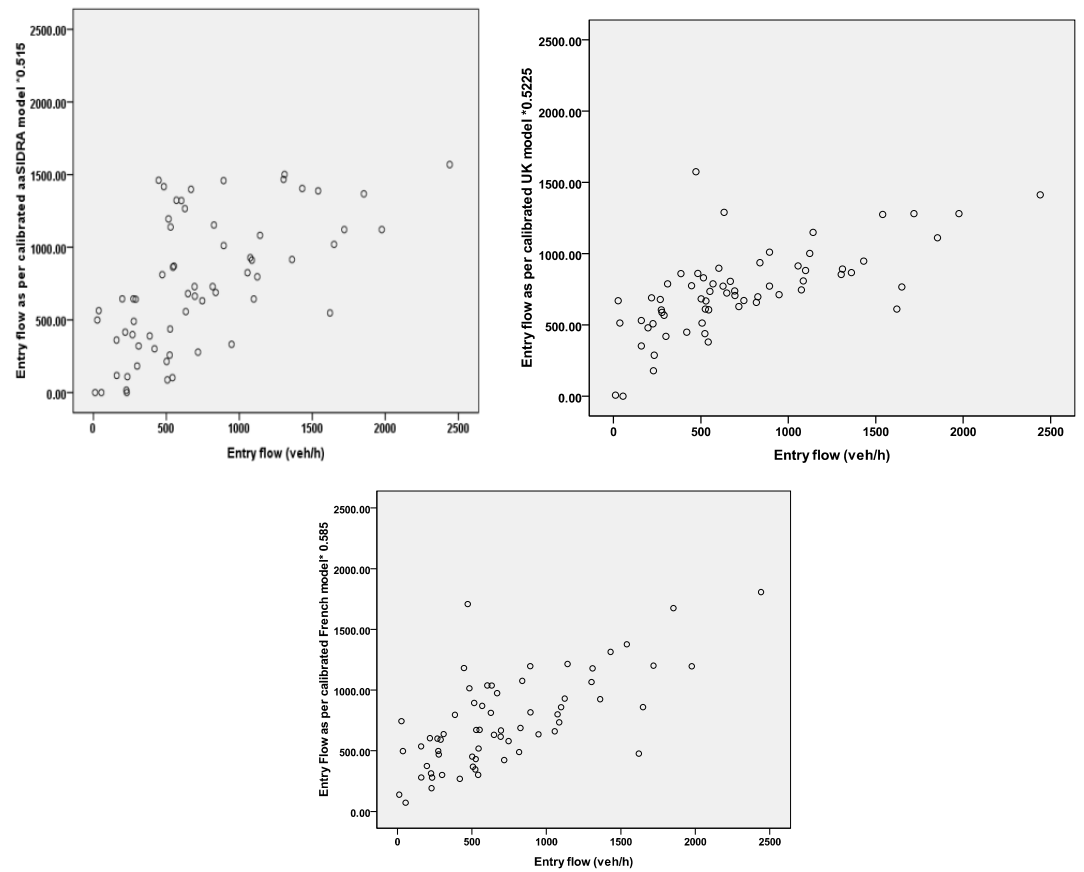

Figure 1: $\quad$ Entry capacity of calibrated aaSIDRA, UK and French models vs. actual data. 

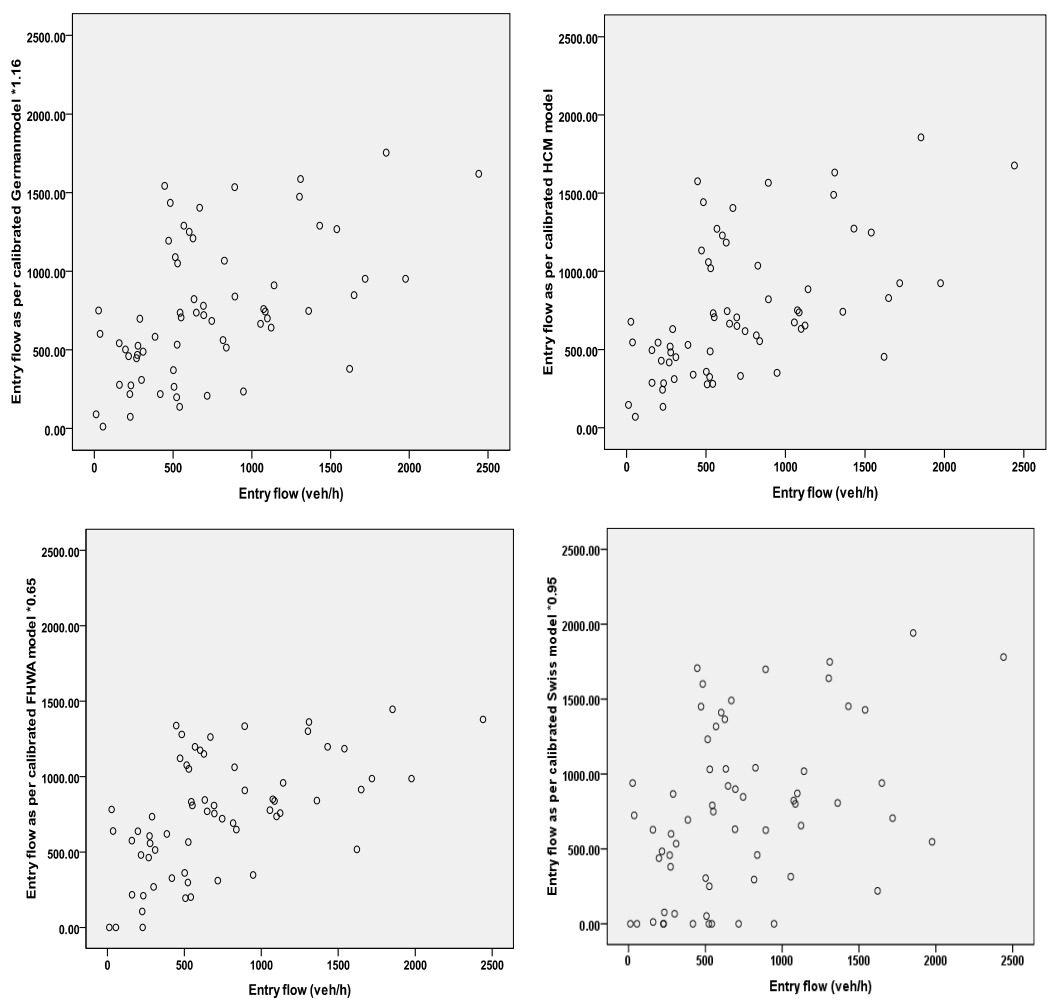

Figure 2: Entry capacity of calibrated German, US HCM, US FHWA and Swiss models vs. actual data.

Both standard deviation and standard error of mean (SEM) have improved substantially after the models being calibrated, except the German model. The $\mathrm{HCM}$ remained as is, since it did not required any adjustment. All the calibrated models showed significant association with the field data; consequently the paired t-test, as can be observed from Table 4, showed high insignificant differences between calibrated capacities and actual data. These mean that entry flows obtained through each of the earlier calibrated models match well those collected from the field in Bahrain. However, both the standard deviation and RMSE of each calibrated model showed clear variation between the calibrated models and the actual data. The scatter plots of the predicted entry capacities of the earlier calibrated models versus the actual field data also confirm clear deviation. Nevertheless, the pattern of the data in the scattered diagrams is generally oriented around $45^{\circ}$ shape. Calibrated UK and French models show reasonable match with actual data, regardless of few clearly outlaying data points (Figure 1). The following international models required the greatest adjustments to reasonably match the field data in Bahrain (Table 3): aaSIDRA, UK and French models. Their corresponding adjustment factors, based on the lowest 
RMSE (Table 3), Standard Error of Means and paired t-tests (Table 4) between the predicted entry capacity of the calibrated international models and the field data, were as follows: $0.515,0.5225$ and 0.585 , respectively. The earlier factors reveal high over-predictions of entry capacity of dual-lane roundabouts. These present 72 to $94 \%$ higher estimates than those gathered from the field. Once again, all the earlier models involve quite extensive geometric parameters and mathematical calculations when compared with other international models. On the other hand, the HCM method required no adjustment factor and the Swiss model required minimal adjustments to match the actual data. The adjustment factor for the Swiss model showed only 5\% overestimation of the original model when compared with the actual data. However, the scattered diagram (Figure 2) shows clear deviation of the various data points from the expected $45^{\circ}$ trend between the actual data and that predicted from the calibrated Swiss model. The French model showed the least deviation between the data points when compared with the other models (Figures 1-2). The HCM, German and FHWA models also showed acceptable grouping of the data, around the $45^{\circ}$, compared with Swiss, UK and aaSIDRA models. The data from calibrated UK model, as can be observed from Figure 1, are not well grouped at $45^{\circ}$ nor does it initiate from zero origin. The FHWA model required an adjustment factor of 0.65 . In other words, the FHWA model overestimates the roundabout entry capacity in Bahrain by around 35\%. The German model underestimates the capacity by around $16 \%$. It is quite interesting to mention that the latter four models involve no geometric parameters for the estimation of entry capacity. They are mainly circulating flow dependent.

Table 4: $\quad$ Paired t-test and differences between 2-lane roundabout calibrated models and field data.

\begin{tabular}{|c|r|r|r|r|r|}
\hline \multirow{2}{*}{ Tested Pairs } & \multicolumn{4}{|c|}{} & \multicolumn{2}{c|}{ 2-tailed } \\
\cline { 2 - 6 } Entry flow-calibrated model & Mean & Std. Dev. & SEM & \multicolumn{1}{|c|}{ t-test } & Significance \\
\hline UK $(* 0.5225)$ & 0.6 & 430.6 & 51.5 & 0.011 & .991 \\
aaSIDRA $(* 0.515)$ & 2.4 & 474.4 & 56.7 & 0.042 & .966 \\
French $(* 0.585)$ & -2.8 & 425.0 & 50.8 & -0.055 & .956 \\
German $(* 1.16)$ & 1.3 & 512.9 & 61.3 & 0.023 & .982 \\
Swiss $(* 0.95)$ & 0.7 & 617.0 & 73.8 & 0.010 & .992 \\
HCM $(* 1.0)$ & -0.7 & 489.7 & 58.5 & -0.013 & .990 \\
FHWA $(* 0.65)$ & -0.7 & 482.6 & 57.7 & -0.012 & .990 \\
\hline
\end{tabular}

The questions of why simpler models require little adjustments to suite the regional use when compared with more complicated and comprehensive ones, why various models require varying calibration factors for the very same data points and why the models greatly deviate from the actual field data? Call for further investigation. Nevertheless, while part of the reason might be due to the 
behavioural differences between the drivers in various parts of the world, leading to differences in the drivers response towards acceptable entry headways, another part might be due to the nature of the international model development, considered variables, assumptions made and accuracy of gathered data. Moreover, the data for most of the models were collected for the general use of the model development; the capacity prediction during forced flow conditions might lead to different estimates because of the impeded entering, circulating and exiting flows. Akçelik et al. [21,22] also observed clear reductions in capacity during high demand flows. Such differences at saturated flows were questioned by Russell and Rys [7], especially when gap acceptance models are used at near capacity conditions. Stanek and Milam [10] also questioned the suitability of UK RODEL and aaSIDRA models during saturation flows. Furthermore, noncalibrated UK model overestimated roundabout critical lane capacity in the USA, as well $[11,18]$.

Though the calibrated models showed substantial improvements in the capacity prediction, when compared with actual data; the scatter plots (Figures 1 to 4) and the RMSE still present clear deviations from the field data. Confirming the above discussed reasons, this partially might be due nature of any traffic data during forced flow conditions at any junctions [35]. The data collected here for the various roundabouts might generally be classified as uneven. Differences in average vehicle length, between different parts of the worlds, might lead to varying capacity estimates from the original model, since the average vehicle length in the Arabian Gulf area is probably higher than that in Britain, Australia, France and many other developed countries. Average vehicle length in this region might be comparable with that in the States, Switzerland and Germany. Geometric differences might also have influence, as well. For example, the roundabouts used in this study are considered to be relatively large. The Swiss model is based on small roundabouts. Other models did not specified average roundabout diameter. All these, along with many others, need to be further researched to recalibrate the earlier stated adjustment factors.

\section{Conclusions and recommendations}

This study attempts to calibrate 7 international models for the use during forced flow conditions in Bahrain. The considered models include UK, aaSIDRA, Swiss, US FHWA, US HCM, French and German models. The models are compared with the actual field data collected from 12 large roundabouts. They showed wide varying estimates for the roundabouts under study. The calibrations are considered using scattered plots, Root Mean Square Error (RMSE) and ttests. Each international model is calibrated by a trial multiplicative factor which is then increased and decreased in iterative manner until best match with actual data is achieved. The calibration factors showed high variations in the adjustment factors between one model and another. However, the calibrated models showed substantial improvements in the predicted capacities when compared with the actual data. Though the RMSE improved substantially, they still require further improvements. The UK, aaSIDRA and French models 
required the greatest adjustments to suite the field data. They required over $40 \%$ reduction to reasonably match the actual data. The HCM method required no adjustments and the Swiss model required a reduction of 5\%. The calibration factors were as follows for UK, aaSIDRA, French, FHWA, German, HCM and Swiss: $0.5225,0.515,0.585,0.65,1.16,1.0$ and 0.95 , respectively. The calibrated models assist the planners and the consultant offices to have just predictions regarding roundabout capacities during saturated flow conditions. The developed calibrations require further investigation to reduce the deviation between the calibrated models and the actual data.

\section{Acknowledgement}

The author wishes to thank Z. Saleh, A. Jaafar, H. Qadhi and Bahrain Road Directorate, Ministry of Public Work for their assistance in gathering the data.

\section{References}

[1] Akçelik and Associates "aaSIDRA 2.1 in put Guide." Revised version, Akçelik and Associates Pty Ltd, Greythorn, Melbourne, Australia, 2005.

[2] E. Hollis, M. C., Semmens S.L. Dennis "ARCADY: A Computer Program to Model Capacities, Queues and Delays at Roundabouts" Transport and Road Research Laboratories, Crowthorne, Report LR 940, 1982.

[3] G. Tenekci, F. Montgomery, S. Wainaina "Roundabout Capacity in Adverse Weather and Light Conditions" Transport, 163, 29-39, Proceedings of the Institution of Civil Engineers, 2010.

[4] Transportation Research Board "Highway Capacity Manual 2000." National Research Council, TRB, SR 209, Washington D.C., 2010.

[5] National Cooperative Highway Research Program "Appendixes to NCHRP Report 572: Roundabouts in the United States", NCHRP Web-Only Document 94, Final Report for NCHRP Project 3-65, USA, 2006.

[6] Kimber, R. M. "Gap acceptance and empiricism in capacity prediction." Transportation Science, 23 (2), 100-111, 1989.

[7] Russell, E. and Rys, M. "Modeling traffic flows and capacities at roundabout." MBTC 1099, Kansas State University, Manhattan, USA, 2000.

[8] Fisk, C. S. "Traffic performance analysis at roundabouts." Transportation Research, 25B, 89-102, 1991.

[9] Boxill, S. A., 2007. "An evaluation of 3-D traffic simulation modeling capabilities". Report 167621-1, Center for Transportation Training and Research, Texas, Southern University, Houston, USA, 2007.

[10] Stanek, D., and Milam, R. T. "High-Capacity roundabout intersection analysis: going around in circles." National Roundabout Conference, TRB, Colorado, USA, 2005.

[11] Al-Madani H. M. N. "Capacity of Large Dual and Triple-Lanes Roundabouts during Heavy Demand Conditions" Arabian Journal for 
Science and Engineering, Engineering, King Fahad University of Petroleum and Minerals, Dhahran, Saudi Arabia (accepted), 2011.

[12] Al-Madani, H. M. N. "Capacity of Large Dual and Triple-Lanes Roundabouts during Heavy Demand Conditions" Arabian Journal for Science and Engineering, King Fahad University of Petroleum and Minerals, Saudi Arabia, (In Press), 2011.

[13] Pratelli, A. "Design of modern roundabout in urban traffic system." WIT Transactions on the Built Environment, vol. 89, Proceedings Urban Transport XII Urban Transport and the Environment. Ed. Brebbia, C. A., WIT press, UK, 2006.

[14] Jacquemart, G. "Modern Roundabout Practice in the United States." Synthesis of Highway Practice 264, Transportation Research Board, Washington, D.C., USA, 1998.

[15] Crown, R. B. "RODEL1: Interactive Roundabout Design (Software Manual)." RODEL Software Ltd. and Council Stoke-on-Trent, 1987.

[16] Kimber, R. M., and Hollis, M., "Traffic queues and delays at road junctions." Transport and Road Research Laboratory, LR909, Crowthorne, Berkshire, UK, 1979.

[17] Kimber, R. M. "The traffic capacity of roundabouts". TRRL, LR942, Crowthorne, Berkshire, UK, 1980.

[18] Robinson, B. W. and Rodegerdts, L. A., "Capacity and performance of roundabouts: a summary of recommendations in the FHWA roundabout guide." Kitttelson and Associates, Inc., USA, 2009. //ntl.bts.gov/lib /8000/8500/8596/36_29.pdf// (as on 10 ${ }^{\text {th }}$ Dec. 2009).

[19] National Cooperative Highway Research Programs (NCHRP) "Roundabouts in the United States" NCHRP report 572, Transportation Research Board, Washington, D.C., 2007.

[20] Transportation Research Board "Highway Capacity Manual 2000." National Research Council, TRB, SR 209, Washington D.C., 2000.

[21] Akçelik, R., Chung, E., and Besley, M., "Performance of roundabouts under heavy demand conditions." Road and Transport Research, 5(2), 3650, Victoria, Australia, 1996.

[22] Akçelik, R., Chung, E., and Besley, M., "Roundabouts: capacity and performance analysis." Research Report APR 321, ARRB, Transport Research Ltd., Vermon South, Australia, 1998.

[23] National Association of Australian State Road Authorities, NAASRA "Guide to Traffic Engineering Practice - Intersections at Grade." Part 5, National Association of Australian State Road Authorities, Sydney, Australia, 1998.

[24] National Association of Australian State Road Authorities, NAASRA "Guide to Traffic Engineering Practice- Roundabouts." Part 6, AP-G11.6, National Association of Australian State Road Authorities, Sydney, Australia, 1998.

[25] Adams, M., Barker, D., and Rye, T. "Roundabouts. Unit 9.” BE71008: Highway Planning and Design. Third Edition, Napier University, School of the Built Environment, Scotland, UK, 2004. 
[26] German Highway Capacity Manual "Handbook for assessing road traffic facilities (Forschungsgesellschaft fur das Strassen und Verkehrswesen, Handbuch fur die Bemessung von StraBenverkehrsanlagen, HBS)." FGSV, no. 299, Verlag Gmbh, Koln, Germany, 2001.

[27] Brilon, W., Wu, N., and Bondzio, L. "Unsignalized intersections in Germany - A State of the Art." In Proceedings of the Third International Symposium on Intersections Without Traffic Signals (M. Kyte ed.), University of Idaho, Portland, Oregon, USA, 1997.

[28] Wu, N. "Capacity of shared- short lanes at unsignalized intersections." In Proceedings of the Third International Symposium on Intersections Without Traffic Signals (M. Kyte ed.), University of Idaho, Portland, Oregon, USA, 1997.

[29] $\mathrm{Wu}, \mathrm{N}$. A. "Universal procedure for capacity determination at unsignalized (Priority-Controlled) intersections." Transportation Research B, 35, 3, USA, 2001.

[30] Lough, G. "Panaroma critique des models Francais de capacite des carrefours giratoires." Proceedings of the seminar Roundabouts 92, SETRA, BP 100, F 92223 Bagneux, Nantes, France, 1992.

[31] GIRABASE "Calculation of roundabout capacity." www.certu.fr as at June 2008.

[32] Federal Highway Administration -FHWA "Roundabouts: An Information Guide.” FHWA- RD-00-067, US Department of Transport, Virginia, USA, 2000.

[33] Al-Madani, H. M. N., and Saad, M., "Analysis of roundabout capacity under high demand flows." WIT Transactions on the Built Environment, vol. 107, Proceedings Urban Transport XV Urban Transport and the Environment. Ed. Brebbia, C. A., 223-234, WIT press, UK, 2009.

[34] Montgomery, D. C. and Runger, G. C., Applied Statistics and Probability for Engineers, $3^{\text {rd }}$ Edition, John Wiley, Denver, USA, 2003.

[35] Al-Madani H. M. N., Dynamic vehicular delay comparison between a police-controlled roundabout and a traffic signal, Transportation Research, 37A, 681- 688, 2003. 